\title{
Development and Validation of Methods for Identification and Quantification of Biological Active Substances in the Fruit of Tetrapleura tetraptera
}

\author{
Ebenezer Frimpong*, Liliya Logoyda \\ Department of Pharmaceutical Chemistry, Ternopil State Medical University, Ternopil, Ukraine \\ Email: *pharmeben@gmail.com
}

How to cite this paper: Frimpong, E. and Logoyda, L. (2020) Development and Validation of Methods for Identification and Quantification of Biological Active Substances in the Fruit of Tetrapleura tetraptera. American Journal of Analytical Chemistry, 11, 335-348.

https://doi.org/10.4236/ajac.2020.119027

Received: September 1, 2020

Accepted: September 24, 2020

Published: September 27, 2020

Copyright $\odot 2020$ by author(s) and Scientific Research Publishing Inc. This work is licensed under the Creative Commons Attribution International License (CC BY 4.0).

http://creativecommons.org/licenses/by/4.0/

\begin{abstract}
This study was conducted to identify the biological active substances (BAS) from the fruit of Tetrapleura tetraptera obtained from Ghana. TLC, UV Spectroscopy and differential spectrophotometry methods of analysis were employed in this study. Identified BAS included flavonoids, polysaccharides and amino acids. Following state pharmacopoeia of Ukraine (SPU) requirements to validate the developed techniques were employed in this study, and the following validation properties specificity, linearity, range, precision accuracy (convergence) and robustness was determined. These characteristics did not exceed the eligibility criteria as stated in (SPU) Appendix 2. Thus the technique can be made to the SPU monograph on fruits of Tetrapleura tetraptera.
\end{abstract}

\section{Keywords}

Biological Active Substances, Tetrapleura tetraptera, SPU

\section{Introduction}

The medicinal plant Tetrapleura tetraptera belongs to the family Mimosaceae. It is known as prekese by the Akan population in Ghana. In Nigeria, the Yorubas called it aridan while the Igbos called it oshosho [1]. Tetrapleura tetraptera is a perennial plant with dark green leaves and mostly found in the rain forest belt of the West, Eastern and Central sub-regions on the African continent [2] [3]. The major bioactive compounds found in Tetrapleura tetraptera are saponins, tannins, phenols, flavonoids and glycosides [3]. Tettrapleura tetraptera is used by 
the indigenous population in Africa for the treatment of hypertension, asthma, schistosomiasis and epilepsy [4].

The present study examines the development of methods for identification and quantification of biologically active substances (BAS) found in the fruit of Tetrapleura tetraptera.

\section{Instruments and Reagents}

Analytical equipment: UV spectrophotometer Carry 50, Scales AVT-120-5D, measuring vessel glass and reagents, which met SPU requirements. TLC test was carried out using Silica gel, chromatographic plates 60 F254 (company "Merck", Germany) and "Sorbfil" (Russia).

Table 1 presents the reagents and their methods of preparation employed in this study.

It is significant to point out that other used reagents solutions were prepared per the requirements of SPU [5].

\section{Development of Methods for Identification of BAS in Tetrapleura tetraptera}

To develop methods of identification and quantification of BAS in Tetrapleura tetraptera, we employed chemical and physicochemical (TLC, UV spectrophotometry and differential adsorption spectrophotometry) methods of analysis.

Table 1. Reagents and their methods of preparation.

\begin{tabular}{|c|c|}
\hline Reagents & preparation \\
\hline & $3 \mathrm{~g}$ of aluminum chloride $\mathrm{AlCl}_{3} \cdot 6 \mathrm{H}_{2} \mathrm{O}$ was \\
\hline $3 \%$ solution of aluminium chloride & $\begin{array}{l}\text { placed in a volumetric flask of } 100 \mathrm{ml}, 70 \mathrm{ml} \text { of } \\
\text { alcohol } 70 \%(\mathrm{v} / \mathrm{v}) \text { was added to dissolve, and } \\
\text { adjusted volume solution of the same solvent } \\
\text { was added to the mark and mixed. The freshly } \\
\text { prepared solution was used. }\end{array}$ \\
\hline $10 \%, 40 \%$ sodium hydroxide & $\begin{array}{l}10 \mathrm{~g} \text { ( } 40 \mathrm{~g}) \text { of sodium hydroxide } \mathrm{NaOH} \text { was } \\
\text { placed in a volumetric flask of } 100 \mathrm{ml}, 70 \mathrm{ml} \\
\text { of distilled water R added, dissolved and ad- } \\
\text { justed volume of the solution of the same sol- } \\
\text { vent was added to the mark and mixed. }\end{array}$ \\
\hline $1 \%$ solution of picric acid & $\begin{array}{l}1 \mathrm{~g} \text { picric acid was placed in a volumetric flask } \\
\text { of } 100 \mathrm{ml}, 70 \mathrm{ml} \text { of distilled water } \mathrm{R} \text { was added, } \\
\text { dissolved and adjusted to the same volume of } \\
\text { the solution to the mark with solvent, stirred. } \\
\text { The freshly prepared solution was used. }\end{array}$ \\
\hline $20 \%$ solution of sodium carbonate & $\begin{array}{l}20 \mathrm{~g} \text { of sodium carbonate } \mathrm{Na}_{2} \mathrm{CO}_{3} \text { was placed } \\
\text { in a volumetric flask of } 100 \mathrm{ml}, 70 \mathrm{ml} \text { of } \\
\text { distilled water } \mathrm{R} \text { was added, dissolved and } \\
\text { adjusted to the same volume of the solution } \\
\text { to the mark with solvent and stirred. The } \\
\text { freshly prepared solution was used. }\end{array}$ \\
\hline
\end{tabular}




\subsection{Development and Validation of Methods for Identification of BAS in Fruits of Tetrapleura tetraptera}

Investigation of the quality of the phenolic compounds in Tetrapleura tetraptera was performed using, these reference solutions (solutions standard samples) apigenin, apigenin-7-O-glucoside, luteolin, leuteonin-7-O-glucoside, hyperoside, rutin, rosmaric acid, chlorogenic acid and caffeic acid. The analysis evaluated visually by watching chromatographic plate under UV light at wavelengths-254 and $356 \mathrm{~nm}$ and after viewed chromatogram of the ether solution aminoethyldiphenylboric acid and macrogol 400 in methanol.

TLC-technique for identification of phenolic compounds was as follows:

Test solution (a). $1000 \mathrm{~g}$ of fruits from Tetrapleura tetraptera ( $2 \mathrm{ml}$ of liquid) was placed in a conical flask $50 \mathrm{ml}, 20 \mathrm{ml}$ of $60 \%$ alcohol $(60 \%(\mathrm{v} / \mathrm{v}))$ was added and heated, in a water bath under reflux for $45 \mathrm{~min}$. The solution was cooled and filtered through a filter "blue ribbon" in the volumetric flask, and $25 \mathrm{ml}$ of the same solvent was diluted to the mark.

Test solution (a). $1000 \mathrm{~g}$ of fruits of Tetrapleura tetraptera ( $2 \mathrm{ml}$ of liquid) placed in a conical flask $50 \mathrm{ml}, 20 \mathrm{ml}$ of methanol $R$ was added and boiled in a water bath under reflux for $45 \mathrm{~min}$. The solution was cooled and filtered through a filter "blue ribbon" in the volumetric flask and $25 \mathrm{ml}$ of the same solvent was diluted to the mark.

Reference solution (a, b) $2.5 \mathrm{mg}$ of standard sample apigenin-7-O-glucoside (Fluka), $2.5 \mathrm{mg}$ apigenin standard sample (Fluka), $2.5 \mathrm{mg}$ standard sample luteolin-7-O-glucoside (CRS), $2.5 \mathrm{mg}$ of standard sample luteolin (Fluka), $2.5 \mathrm{mg}$ of rutin standard sample (Sigma), $2.5 \mathrm{mg}$ of chlorogenic acid standard sample (Fluka), $2.5 \mathrm{mg}$ standard sample a coffee acid (Fluka), $2.5 \mathrm{mg}$ rosmaric acid standard sample (Fluka), $2.5 \mathrm{mg}$ standard sample cicoric acid (Fluka) were dissolved in $25 \mathrm{ml}$ of methanol R. $10 \mathrm{ml}$ extract obtained (test solution (a) and (c)) and $5 \mathrm{ml}$ solutions of substances witnesses (solution comparison) were put together.

Plates coated samples dried in air and placed in a chromatography chamber, with solvent mixture ethyl acetate $R$-formic acid $P$ - $P$ water (90:6:9).

Anytime, the solvent front was held $15 \mathrm{~cm}$ from the starting line and the plate was removed from the camera. The plates were dried in air and then kept, at a temperature of $100^{\circ} \mathrm{C}$ to $105^{\circ} \mathrm{C}$ for 2 minutes. The heated plate was sprayed with a solution of $10 \mathrm{~g} / \mathrm{L}$ ether solution amino ethyldiphenyl boric acid and macrogol 400 in methanol and dried in air. The plate was then sprayed with a solution of $50 \mathrm{~g} / \mathrm{L}$ macrogol 400 in methanol, air-dried for $30 \mathrm{~min}$ and viewed under UV light with a wavelength of $365 \mathrm{~nm}$. The analysis evaluated visually by watching chromatographic plate under UV light at wavelengths -254 and $356 \mathrm{~nm}$ and chromatogram of the ether solution aminoethyldiphenylboric acid and macrogol 400 in methanol were observed afterwards as shown in (Figure 1).

\subsection{Determination of the Quantitative Amounts of Flavonoids Contents in Alcoholic Extracts of Tetrapleura tetraptera}

To study the effect of concentration of alcohol in the degree of extraction of 


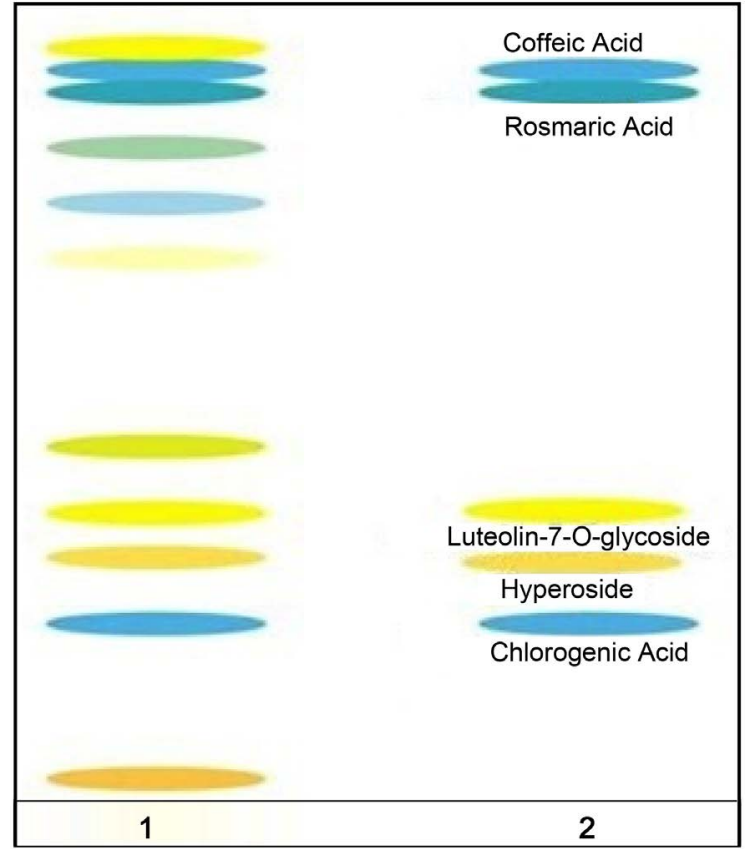

Figure 1. Scheme chromatograms in terms of identification of phenolic compounds in fruit of Tetrapleura tetraptera after treatment with a solution of diphenyl boric acid 2-amino ethyl ester, when viewed in ultraviolet light with a wavelength of $365 \mathrm{~nm}$ (solvent system $-\mathrm{R}$ acetate-formic acid R-R water (90:6:9).

flavonoids, alcoholic extracts were obtained using aqueous solutions of ethyl alcohol (varying its content from 0 to $96 \%$ ) by heating a sample of the crushed material, with an appropriate alcohol solution in a boiling water bath for $45 \mathrm{mi}-$ nutes and getting $100 \mathrm{ml}$ of the appropriate lift.

Table 2 presents the quantitative determination of flavonoids in ethanol extracts.

Table 2. Quantitative determination of flavonoids in ethanol extracts, Tetrapleura tetraptera $(\mathrm{p}=0.95, \mathrm{n}=5)$.

\begin{tabular}{cc}
\hline $\begin{array}{c}\text { The content of ethyl alcohol in the } \\
\text { used extractant } \%\end{array}$ & $\begin{array}{c}\text { Content amount of flavonoids in the excerpt, } \\
\text { in terms of apigenin, } \times 10^{3} \%\end{array}$ \\
\hline 0 & $4.9 \pm 0.1$ \\
10 & $5.4 \pm 0.2$ \\
20 & $5.4 \pm 0.2$ \\
30 & $5.4 \pm 0.2$ \\
40 & $5.6 \pm 0.1$ \\
50 & $5.6 \pm 0.2$ \\
60 & $6.1 \pm 0.1$ \\
70 & $5.8 \pm 0.1$ \\
80 & $5.2 \pm 0.2$ \\
90 & $4.0 \pm 0.2$ \\
96 & $2.9 \pm 0.1$ \\
\hline
\end{tabular}


The content of flavonoids was determined by differential spectrophotometry (reaction with aluminium chloride). As a compensation solution, using the stock solution without the addition of appropriate reagents makes it impossible to influence stained and related substances. In the differential electronic absorption spectrum for the complex of aluminum chloride, apigenin position characteristic maximum was at $390 \pm 2 \mathrm{~nm}$ and explored for solutions in similar circumstances at $393 \pm 2 \mathrm{~nm}$ (Figure 2).

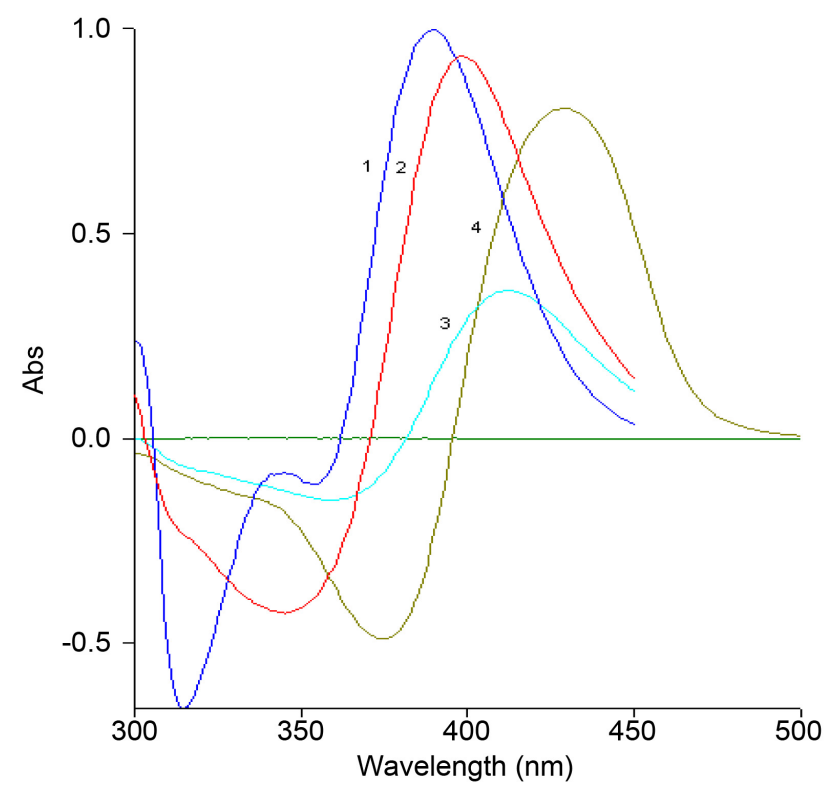

Figure 2. Differential electronic absorption spectra of the test solution flavonoids (Tetrapleura tetraptera) $\left(\lambda_{\max }=393 \mathrm{~nm}\right)$ and standard solutions of flavonoids with aluminum chloride in terms.

Comparing their course and position of the maximum of the appearance and the position of the absorption maximum of a similar set of different flavonoid glycosides and aglycones, we found out that for subjects with seizures, Tetrapleura tetraptera quantitative content should be made to apigenin. In the differential electronic absorption spectrum for the complex of aluminum chloride, apigenin position characteristic maximum was at $390 \pm 2 \mathrm{~nm}$ and explored for solutions in similar circumstances at $393 \pm 2 \mathrm{~nm}$, that is why the quantitative content of flavonoids in the ethanol extracts was calculated in terms of apigenin.

As shown in Table 2, the most complete extraction amounts of flavonoids from Tetrapleura tetraptera was achieved in terms of obtaining alcohol exemptions described above, and the application of alcohol $(60 \%-70 \%(\mathrm{v} / \mathrm{v})$. By increasing the concentration of alcohol in the extractant, flavonoid content did not increase, which indirectly indicates, the presence of both aglicon and flavonoid glycoside forms. Thus, that is why for spectrophotometric determination, we suggest the application of alcoholic extract $60 \%(\mathrm{v} / \mathrm{v})$ ethanol. In a nutshell, you can offer the flavonoid content of not less than $2 \%$ in terms of apigenin and 
propose to quantify the method that is simpler in execution, to obtain objective results with regards to its content.

The content of flavonoids in the amount of raw materials as a percentage, calculated as apigenin and dry raw material $(X)$ was done using the formula:

$$
X=\frac{A_{x} * m_{0}}{A_{0} * m} * 100,
$$

where, $A_{X}$-optical density of the test solution; $A_{0}$-optical density of the reference solution;

$m_{0}$ - the mass of sample standard sample of apigenin, $\mathrm{g}$;

$m$-the mass of sample material, $\mathrm{g}$.

\subsection{A Qualitative Study on Monosaccharides}

Qualitative analysis on monosaccharides was performed by deposition of water-soluble polysaccharide complex from an aqueous extract of fruit $96 \%$ alcohol (the ratio of water withdrawal-alcohol 1:3). The resulting water-soluble polysaccharide complex fruit of Tetrapleura tetraptera was an amorphous precipitate light grey with a brown tinge of colour, soluble in water and insoluble in organic solvents. As a result of qualitative reactions of iodine solution, $1 \%$ solution of iron (III) chloride, $10 \%$ solution of copper sulfate and sodium hydroxide were concluded on starch, phenolic compounds and peptides in a complex test. Along with their composition was investigated by thin layer chromatography. Chromatographic studies were performed on chromatographic plates Silica gel 60F254 ("Merck", Germany) using a mobile phase water R-acetonitrile R (15:85) and trim plates thymol solution P ( $0.5 \mathrm{~g}$ thymol, $0.5 \mathrm{ml}$ of sulfuric acid $\mathrm{R} 95 \mathrm{ml}$ of $96 \%$ alcohol). As witnesses were standard samples of glucose, fructose, arabinose, xylose, rhamnose, galactose, glucuronic and galacturonic acids. As a result, chromatographic studies established the presence of fructose, glucose, arabinose, xylose and rhamnose and galacturonic acid as part of a water-soluble polysaccharide complex of the fruit as shown in Figure 3 below.

Considering the ratio of the sizes and colour intensity of spots on the chromatogram, it was concluded that the predominant sugars were fructose, and with regenerative sugars-glucose, so further calculations regenerative content of monosaccharides were performed in terms of the substance. The content of monosaccharides regenerative in raw materials, as a percentage, calculated as glucose, was done using the formula:

$$
X=\frac{A_{x} * m_{0}}{A_{0} * m} * 100,
$$

where, $A_{x}$-optical density of the test solution; $A_{0}$-optical density standard sample of glucose; $m_{0}-$ mass of sample standard sample of glucose, g; $m$-the mass of sample material, $\mathrm{g}$.

It is significant to point out that the content of regenerative monosaccharides in raw materials, as a percentage, calculated as glucose, should not be less than $2 \%$. 


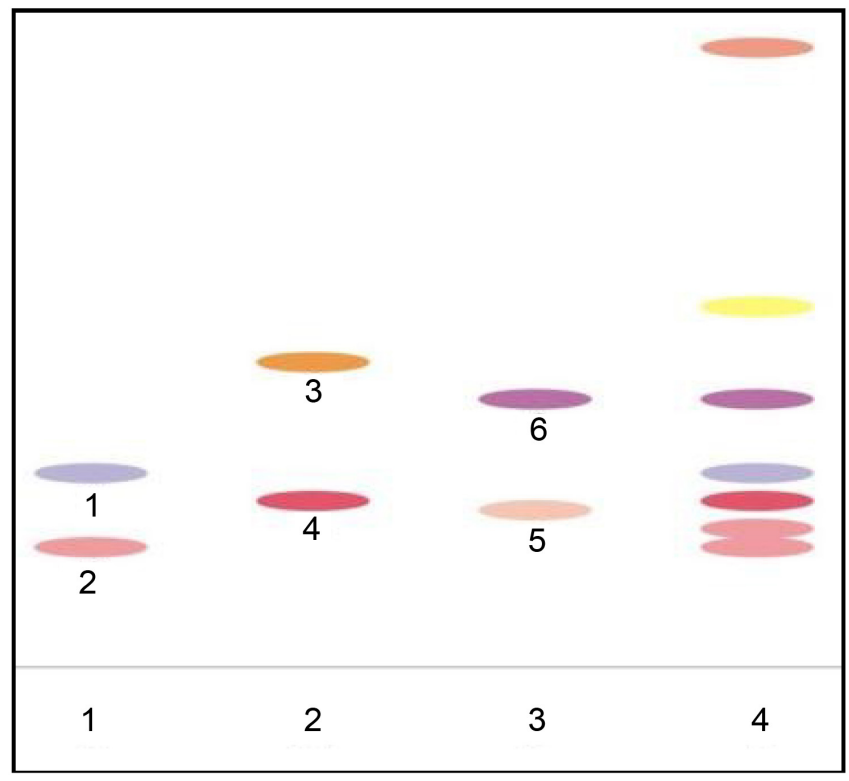

Figure 3. Scheme chromatograms of extracts from fruit Tetrapleura tetraptera (4) and solution (1, 2, 3, where 1-arabinose, 2-galactose, 3-rhamnose, 4-fructose, 5-glucose 6-xylose) in terms of the identification of monosaccharides.

\subsection{Identification and Determination of Forms of Amino Acids in the Fruit of Tetrapleura Tetraptera}

To identify amino acids, we used the method of TLC in different solvent systems: acetate acid R-water R-butanol R (20:20:60), isopropanol R-formiatic acid R-water R (40:2:10), acetone R-water R (3:2). In analyzing the chromatogram, that has the best ability dividing isopropanol mobile phase R-formic acid $\mathrm{R}$-water $\mathrm{R}$ in the ratio (40:2:10). As material witnesses were glycine, alanine, aspartic acid, leucine, glutamic acid and tyrosine. With regards to chromatogram development, a solution of $2 \mathrm{~g} / \mathrm{l}$ ninhydrin ( $5 \mathrm{ml}$ of dilute acetic acid, $95 \mathrm{ml}$ of butanol) was used.

At the starting line chromatographic plate silica gel F254 size $20 \times 20$ with a layer thickness of $0.25 \mathrm{~mm}$ is applied in the form of strips, length $10 \mathrm{~mm}, 20 \mathrm{ml}$ of the test solution and $5 \mathrm{ml}$ reference solution. The plate was dried in air for 10 minutes, placed in a chamber with mobile phase isopropanol R-formic acid R-water R (40:2:10) and ascending chromatography method. When the solvent front will be held $15 \mathrm{~cm}$ from the starting line, it is removed from the chamber and dried in air. The plates were sprayed with a solution of $2 \mathrm{~g} / \mathrm{L}$ ninhydrin $\mathrm{R}$ and heated at $100 \mathrm{C}$ for three to five minutes and viewed in daylight. The scheme chromatogram obtained with the test solution revealed the occurrence of zones of glycine, alanine, tyrosine, leucine, glutamic and aspartic acids in the chromatogram obtained with reference solution as shown in Figure 4.

In selected conditions of the assay, obtained in the photometric coloured reaction product, there were the appearance of two absorption bands at $400 \pm 2 \mathrm{~nm}$ and $567 \pm 2 \mathrm{~nm}$ as shown in Figure 5 below. 


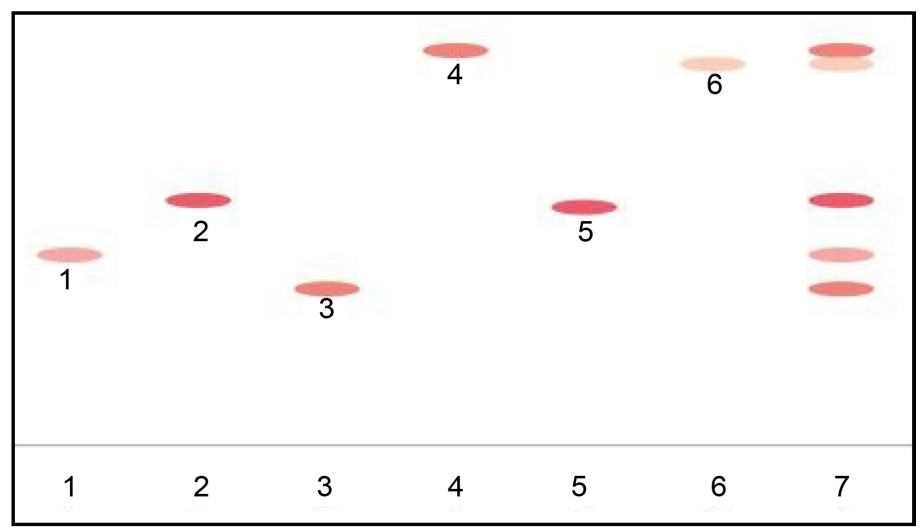

Figure 4. Scheme chromatogram of the test solution (7) and the solution (1-6) was 1-glycine, 2-alanine, 3-aspartic acid, 4-leucine, 5-glutamic acid, 6-tyrosine (solvent system: isopropanol R-formic acid R-R water in the ratio (40:2:10).

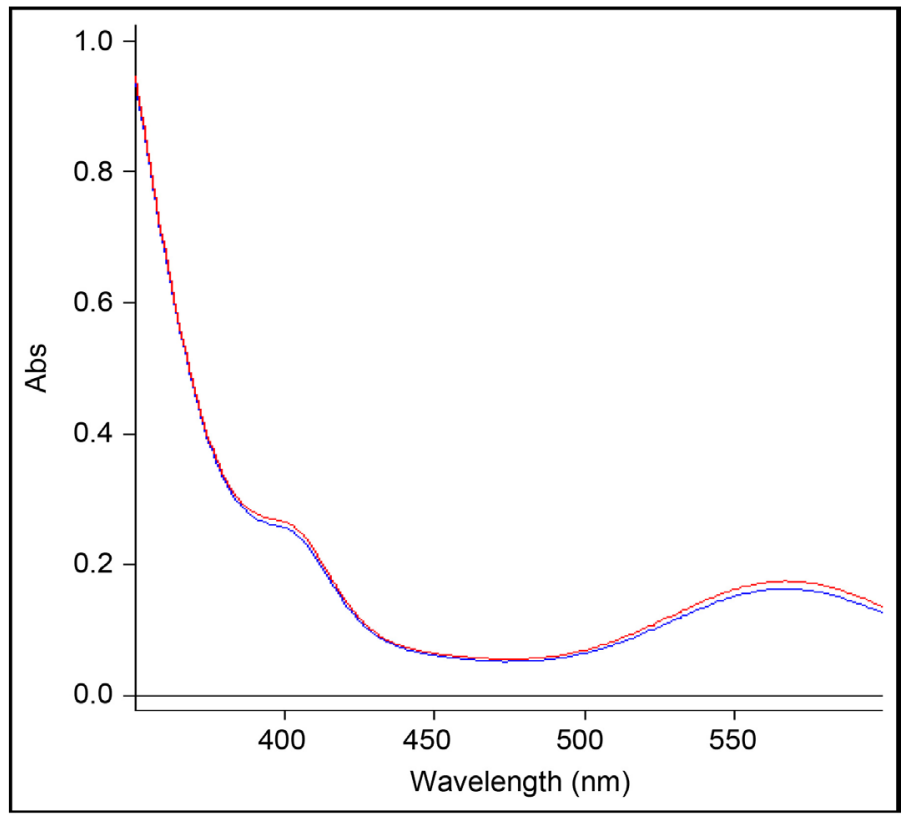

Figure 5. Electronic absorption spectra of solutions of amino acids with ninhydrin in terms of quantification of the 1-test solution obtained for $30 \%$ extractant 2 -Test solution obtained for $40 \%$ of the extractant.

Since at $400 \mathrm{~nm}$ absorbing more hydroxycinnamic acids that present in the recovery, so to measure absorbance compounds should be at a wavelength of 567 nm.

\section{Quantitative Determination of Amino Acids}

Quantitative determination of amino acids was performed by spectrophotometry in the visible range of the known reaction of amino acids coloured product with ninhydrin.

The content of amino acids in fruits of Tetrapleura tetraptera as a percentage 
calculated as glycine, calculated by the formula:

$$
X=\frac{A_{x} * m_{0}}{A_{0} * m} * 10
$$

where, $A_{x}$-optical density of the test solution; $A_{0}$-optical density standard sample of glucose; $m_{0}$-mass of sample standard sample of glucose, g; $m$-the mass of sample material, $\mathrm{g}$.

\subsection{Investigation of Linearity, Accuracy and Precision Using Model Solutions}

As shown in Table 3 below, investigation of linearity, accuracy and precision were studied simultaneously with 9 model solutions, covering a range of concentrations from $60 \%$ to $140 \%$ of the theoretical amount of flavonoids content in terms of apigenin [5] [6] [7] [8]. Based on the determination of the optical density of the solution of accurately known concentration, built graph of absorbance against a concentration of flavonoids in normalized coordinates, is shown using, calculated parameters of linearity. Based on the research, it can be concluded that the linear methods supported the entire range of concentrations studied: the correlation coefficient was equal to 0.99988 and the residual standard deviation was 0.4598 . Graph of absorbance to concentration is almost through the origin (the point of intersection with the ordinate axis -0.1837), computed confidence interval constant confirmed, statistical and practical insignificance of the constants.

Table 3. The results for the determination of linearity on flavonoids.

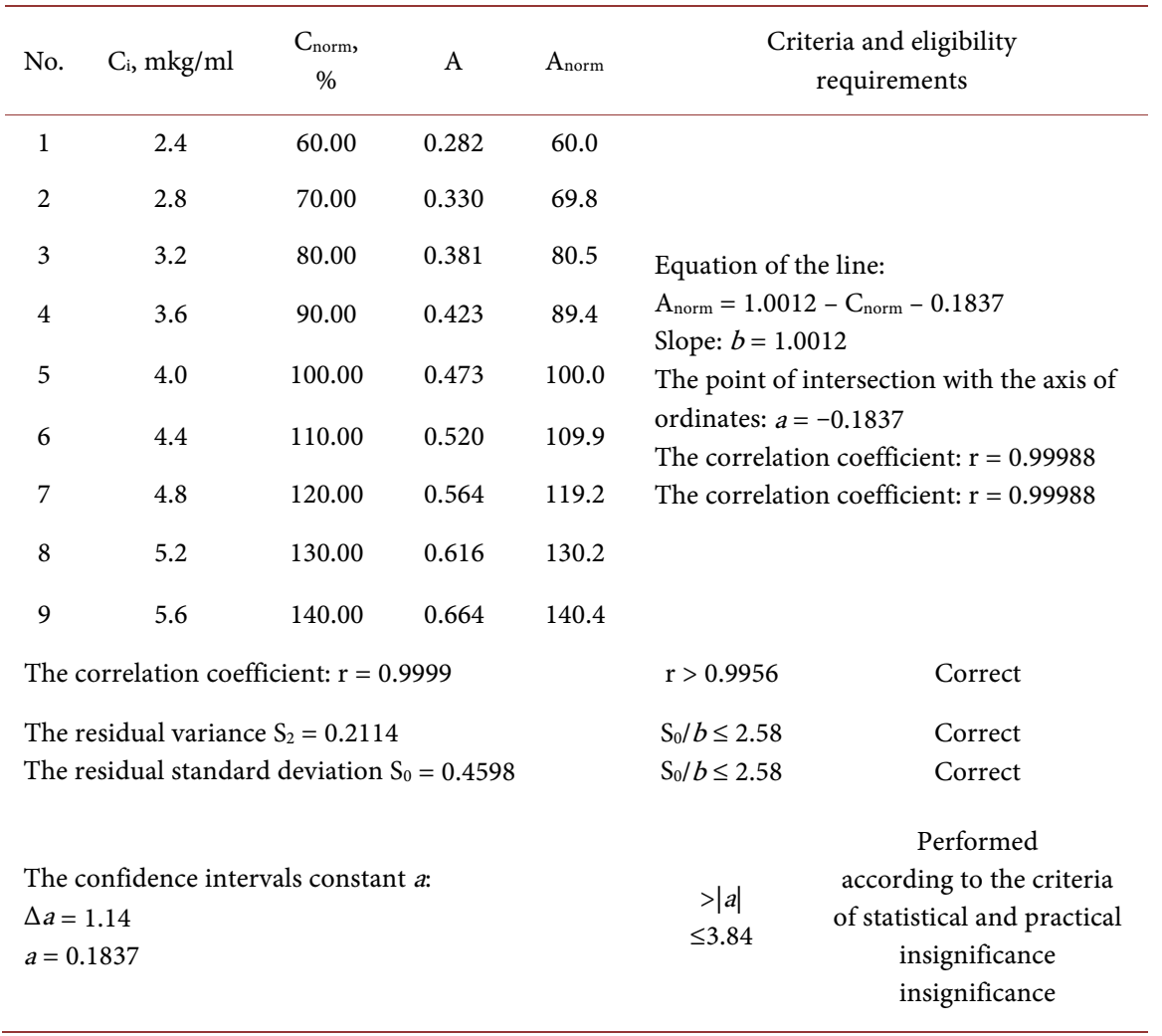


Considering data obtained by a test carried out by "put-found" in Table 4 below, the results of these studies show statistically and practically insignificant systematic error as compared, with the maximum permissible uncertainty analysis. Research of precision (convergence): Convergence technique characterizes the degree of closeness of the results, for a series of measurements by the method of its execution in the same conditions within a short period. Based on the research results presented in Table 4, we can conclude the convergence of the method, since none of the results in the largest error did go beyond the maximum permissible uncertainty analysis.

Table 4 below exhibits the results obtained in the determination of flavonoids on accuracy and convergence.

Table 5 exhibits the results obtained from the determination of linearity on monosaccharides.

Table 6 exhibits test methods for the determining of monosaccharides on the accuracy and convergence.

Table 7 presents the determination of linearity on amino acids.

Table 8 exhibits the determination of the amounts of amino acids regarding accuracy and convergence.

As shown in Table 7 and Table 8, we had done the validation of spectrophotometric methods for the determination of amino acids in the fruit of

Table 4. Results obtained using test methods for determination of flavonoids on accuracy and convergence.

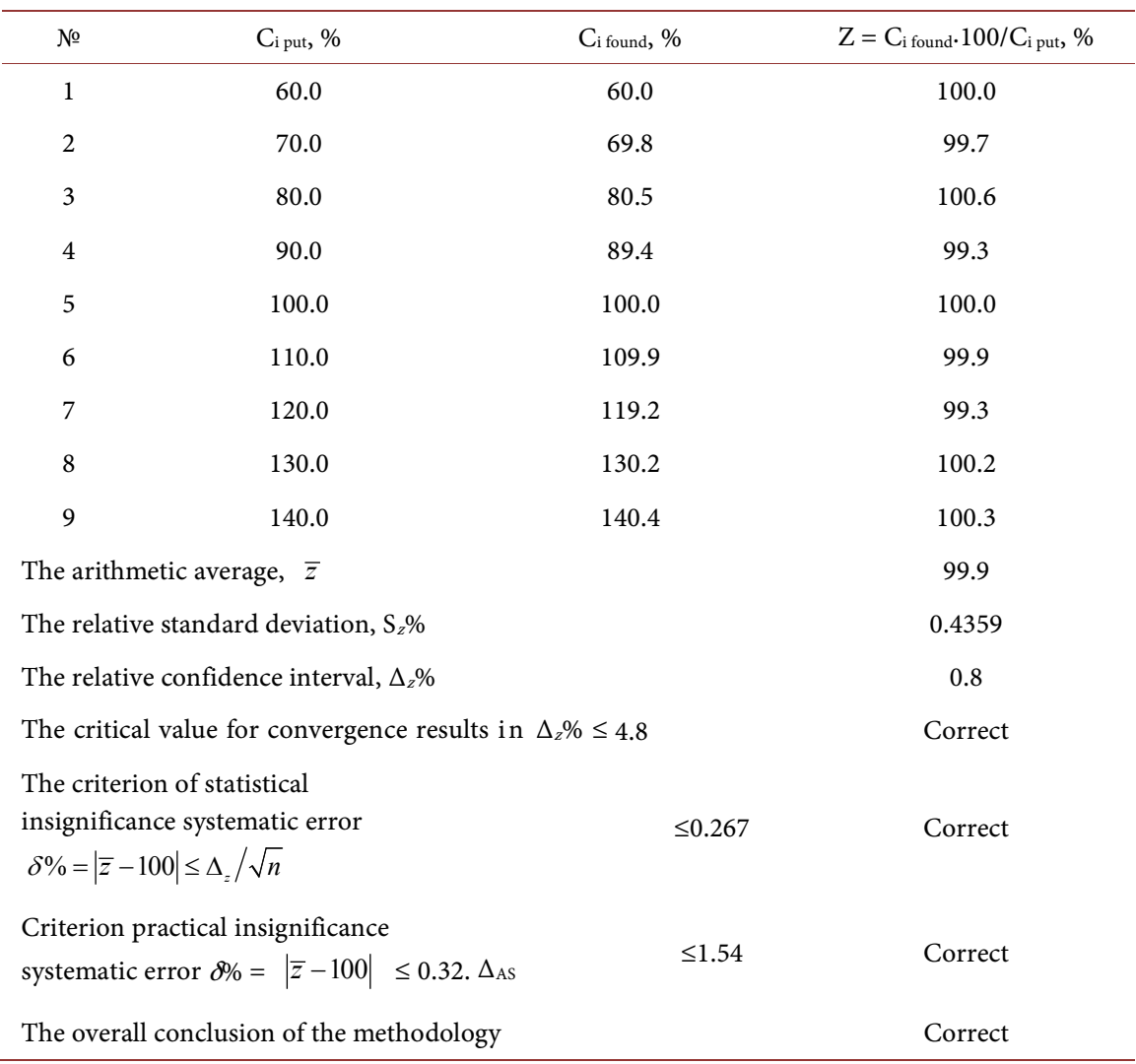


Table 5. Results obtained from the determination of linearity on monosaccharides.

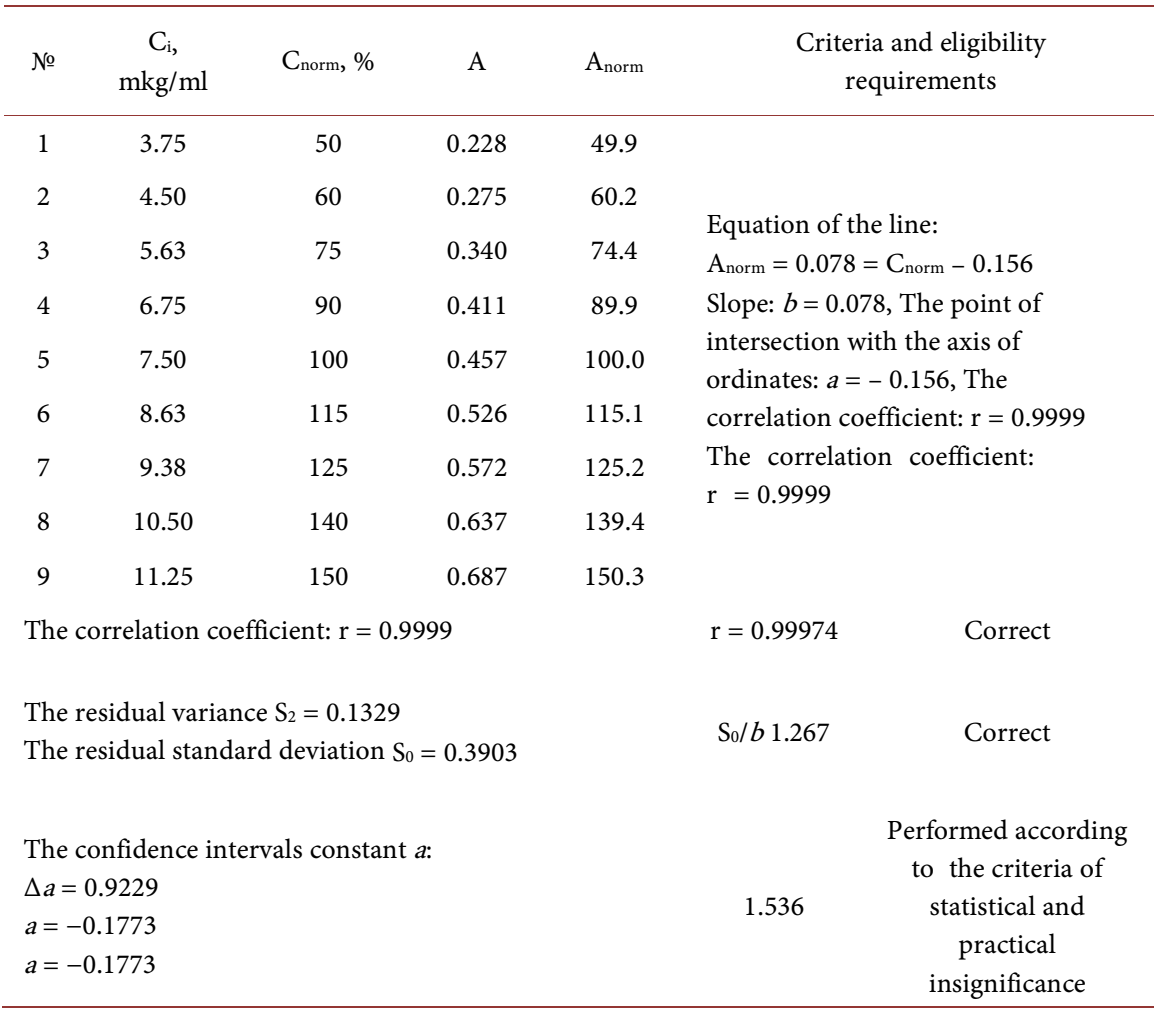

Table 6. The results of the test methods for determining the amounts of monosaccharides on accuracy and convergence.

\begin{tabular}{|c|c|c|c|}
\hline № & $\mathrm{C}_{\mathrm{i} \text { put }} \%$ & $\mathrm{C}_{\mathrm{i} \text { found }}, \%$ & $Z=C_{i \text { found }} \cdot 100 / C_{i}$ put $\%$ \\
\hline 1 & 50 & 49.9 & 99.8 \\
\hline 2 & 60 & 60.2 & 100.3 \\
\hline 3 & 75 & 74.4 & 99.2 \\
\hline 4 & 90 & 89.9 & 99.9 \\
\hline 5 & 100 & 100.0 & 100.0 \\
\hline 6 & 115 & 115.1 & 100.1 \\
\hline 7 & 125 & 125.2 & 100.2 \\
\hline 8 & 140 & 139.4 & 99.6 \\
\hline 9 & 150 & 150.3 & 100.2 \\
\hline \multicolumn{3}{|c|}{ The arithmetic average, $\bar{z}$} & 99.9 \\
\hline \multicolumn{3}{|c|}{ The relative standard deviation, $S_{z} \%$} & 0.35 \\
\hline \multicolumn{3}{|l|}{$z \%$} & 0.65 \\
\hline \multicolumn{2}{|c|}{ The critical value for convergence } & $\leq 4.8$ & Correct \\
\hline \multicolumn{2}{|c|}{$\begin{array}{l}\text { The criterion of statistical } \\
\text { insignificance systematic error } \\
\delta \%=|\bar{z}-100| \leq \Delta_{z} / \sqrt{n}\end{array}$} & $\leq 0.265$ & Correct \\
\hline Criterion practical insignificance & $\begin{array}{l}\text { cance } \\
100 \mid \leq 0.32 . \Delta_{\mathrm{AS}}\end{array}$ & $\leq 1.536$ & $\begin{array}{l}\text { Correct } \\
\text { Correct }\end{array}$ \\
\hline \multicolumn{3}{|c|}{ The overall conclusion of methods used } & Correct \\
\hline
\end{tabular}


Table 7. Determination of linearity on amino acids.

\begin{tabular}{|c|c|c|c|c|c|c|}
\hline № & $\mathrm{C}_{\mathrm{i}} \times 10^{4} \%$ & $\mathrm{C}_{\text {norm}}, \%$ & A & $A_{\text {norm }}$ & \multicolumn{2}{|c|}{$\begin{array}{l}\text { Criteria and eligibility } \\
\text { requirements }\end{array}$} \\
\hline 1 & 3.58 & 50.00 & 0.223 & 49.88 & \multicolumn{2}{|c|}{ Equation of the line: } \\
\hline 2 & 5.01 & 69.97 & 0.315 & 70.47 & \multicolumn{2}{|c|}{$\mathrm{A}_{\text {norm }}=1.0044 \cdot C_{\text {norm }}-0.1871$} \\
\hline 3 & 6.44 & 89.94 & 0.402 & 89.93 & \multicolumn{2}{|c|}{$\begin{array}{l}\text { Slope: } b=1.0044 \\
\text { The point of intersection with the }\end{array}$} \\
\hline 4 & 7.16 & 100.00 & 0.447 & 100 & \multirow{2}{*}{\multicolumn{2}{|c|}{$\begin{array}{l}\text { axis of ordinates: } a=-0.1871 \\
\text { The correlation coefficient: } \\
r=0.99993\end{array}$}} \\
\hline 5 & 7.88 & 110.06 & 0.496 & 110.96 & & \\
\hline 6 & 9.31 & 130.03 & 0.580 & 129.75 & \multirow{2}{*}{\multicolumn{2}{|c|}{$\begin{array}{l}\text { The correlation coefficient: } \\
r=0.99993\end{array}$}} \\
\hline 7 & 10.74 & 150.00 & 0.674 & 150.78 & & \\
\hline \multicolumn{5}{|c|}{ The correlation coefficient: $r=0.99993$} & $r>0.9968$ & Correct \\
\hline \multicolumn{5}{|c|}{$\begin{array}{l}\text { The residual variance } S_{2}=0.2366 \\
\text { The residual standard deviation } S_{0}=0.4864\end{array}$} & \multicolumn{2}{|l|}{$\mathrm{S}_{0} / b \leq 0.9336$} \\
\hline \multicolumn{5}{|c|}{$\begin{array}{l}\text { The confidence intervals constant } a \text { : } \\
\Delta a=1.5722\end{array}$} & $\begin{array}{l}>|a| \\
\leq 1.536\end{array}$ & $\begin{array}{c}\text { Performed } \\
\text { according to the } \\
\text { criteria of statistical } \\
\text { and practical } \\
\text { insignificance }\end{array}$ \\
\hline
\end{tabular}

Table 8. Results obtained from determination of the amounts of amino acids on accuracy and convergence.

\begin{tabular}{|c|c|c|c|}
\hline № & $\mathrm{C}_{\mathrm{i} \text { put }}, \%$ & $\mathrm{C}_{\mathrm{i} \text { found }}, \%$ & $Z=C_{i \text { found }} \cdot 100 / C_{i \text { put }}, \%$ \\
\hline 1 & 50.00 & 49.88 & 99.76 \\
\hline 2 & 69.97 & 70.47 & 100.71 \\
\hline 3 & 89.94 & 89.93 & 99.99 \\
\hline 4 & 100 & 100 & 100.00 \\
\hline 5 & 110.06 & 110.96 & 100.82 \\
\hline 6 & 130.03 & 129.75 & 99.78 \\
\hline 7 & 150.00 & 150.78 & 100.52 \\
\hline \multicolumn{3}{|c|}{ The arithmetic average, $\bar{z}$} & 100.23 \\
\hline \multicolumn{3}{|c|}{ The relative standard deviation, $\mathrm{S}_{\mathrm{z}} \%$} & 0.46 \\
\hline \multicolumn{3}{|c|}{ Relative confidence interval, $\Delta_{z} \%$} & 0.45 \\
\hline \multicolumn{3}{|c|}{$\begin{array}{l}\text { The critical value for convergence results } \\
\Delta_{7} \% \leq 2.4\end{array}$} & Correct \\
\hline & Correct \\
\hline error $\delta$ & $0 \mid \leq 0.32 . \Delta$ & 0.768 & Correct \\
\hline \multicolumn{3}{|c|}{ The overall conclusion of the methodology } & Correct \\
\hline
\end{tabular}

Tetrapleura tetraptera [5] [6] [7] [9]. We have fulfilled the eligibility criteria regarding the validation of performance per the requirements of SPU [5], the technique can be used for the determination of amino acids in the fruit of $T e$ trapleura tetraptera. 


\section{Conclusions}

1) A study of the quality of the flavonoids and phenolcarbonic acids in fruits of Tetrapleuratetraptera. As a result, the presence of flavonoids such as rutin, hyperoside, luteolin-7-O-glucoside, apigenin-7-O-glucoside and luteolin glycoside was confirmed. From phenolcarbinic acids we confirmed rosmaric, chlorogenic and caffeic acids.

2) Developed and tested on different samples of phenolcarbinic acids in fruits of Tetrapleuratetraptera. Method of quantitative determination of flavonoids by differential spectrophotometry was calculated in terms of apigenin. Quantitative criteria on flavonoid content are not less than $2.0 \%$ in terms of apigenin.

3) By TLC and by qualitative reactions identified acidic monosaccharide (galacturonic acid) from sugars identified: glucose, fructose, arabinose, xylose, rhamnose. Quantitative criteria monosaccharide content is not less than $2.0 \%$ in terms of glucose.

4) The first time we had studied the composition of amino acids in fruits of Tetrapleuratetraptera (detected leucine, glycine, tyrosine, alanine, aspartic and glutamic acid). Moreover, developed and tested methods (spectrophotometric) of assay of amino acids calculated in terms of glycine. It was established that different samples of raw content of amino acids are $0.6 \%-1.7 \%$.

5) As a result of our research, we had developed and validated methods for the identification and quantification of biological active substances in Tetrapleuratetraptera.

\section{Conflicts of Interest}

The authors declare no conflicts of interest regarding the publication of this paper.

\section{References}

[1] Joel, J., Sheena, O., Martins, O., Onyemauche, N. and Emmanuel, A. (2017) Comparative Antioxidant Capacity of Aqueous and Ethanol Fruit Extracts of Tetrapleura tetraptera. Journal of Biological Science, 17, 185-193. https://doi.org/10.3923/jbs.2017.185.193

[2] Aladesanmi, A. J. (2007) Tetrapleura tetraptera: Molluscicidal Activity and Chemical Constituents. African Journal of Traditional Complementary and Alternative Medicine, 4, 23-36. https://doi.org/10.4314/ajtcam.v4i1.31189

[3] Famobuwa, O., Lajide, L., Owolabi, B., Osho, I. and Amuho, U. (2016) Antioxidant Activity of the Fruit and Stem Bark of Tetrapleura tetraptera Taub (Mimosaceae). British Journal of Pharmaceutical Research, 9, 1-4. https://doi.org/10.9734/BJPR/2016/21462

[4] Igwe, O.U. and Akabuike, H.C. (2016) Free Radical Scavenging Activity, Phytochemistry and Antimicrobial Properties of Tetrapleura tetraptera Seeds. International Research Journal of Chemistry and Chemical Sciences, 3, 37-42.

[5] State Pharmacopoeia of Ukraine. (2008) Ukraine Pharmacopoeia 2008: Volume III (Supplementary 2), Kharkov.

[6] Grizodub, A.I. (2006) Standard Procedures for Validation of Control Methods 
Quality of Medicines Farmakom. No. 1-2. S. 35-44.

[7] Yurgel, N.V., Mladentsev, A.L., Burdeina, A.V., Getman, M.A. and Malina, A.A. (2007) Guidelines for the Validation of Methods for the Analysis of Drugs Ed., Moscow, $57 \mathrm{p}$.

[8] Zarivna, N.O., Frimpong, E. and Polyak, O.B. (2014) Validation of Quantitative Determination Method of Flavonoids in Fruit of Tetrapleura tetraptera. Key Issues of Scientific Research in the Field of Medicine in the XXI Century: International Scientific Practical Conference, Abstracts. Odessa, 14-15.

[9] Frimpong, E. (2013) Development of Methods of Identification Aminoacids in Fruit Tetrapleura tetraptera, Modern Trends in Medical and Pharmaceutical Sciences. International Scientific and Practical Conference, Kiev, 27-28 December 2013, Abstracts p. 94. 